\title{
Incentivos à igualdade de gênero: estudo de caso de uma comunidade formada somente por mulheres da área de tecnologia
}

\author{
Carolina C. Vieira ${ }^{1}$, Ana Carolina R. Soares ${ }^{1}$, Serena F. Ribeiro ${ }^{2}$ \\ Departamento de Ciência da Computação - Universidade Federal de Minas Gerais (UFMG) \\ Belo Horizonte, MG - Brasil \\ Méliuz \\ Belo Horizonte, MG - Brasil \\ \{carolcoimbra, annesoares\}@dcc.ufmg.br, serena@meliuz.com.br
}

\begin{abstract}
This article presents an initiative whose objective is to reduce the existing gender inequality in the area of Information Technology. The initiative involves the creation of a community as an attempt to minimize prejudice and strengthen women who are part of this sector. The group is formed only by women from the technology field who, through meetings, lectures and courses, seek to empower and encourage the participation of women in the field.
\end{abstract}

Resumo. O artigo apresenta uma iniciativa cujo objetivo é reduzir a desigualdade de gênero existente na área de Tecnologia da Informação. A iniciativa envolve a criação de uma comunidade como tentativa de minimizar o preconceito e fortalecer as mulheres que fazem parte desse setor. O grupo é formado somente por mulheres da área de tecnologia que, através de encontros, palestras e cursos buscam capacitar e incentivar a participação de mulheres na área.

\section{Introdução e Trabalhos Relacionados}

Ao longo dos anos, apesar das inúmeras conquistas femininas nos âmbitos pessoal, social, cultural e profissional, a desigualdade de gênero ainda se mostra presente nessas áreas. Atualmente, essa temática é muito pesquisada [de Freitas and da Luz ] sob várias perspectivas e grandes esforços são feitos para promover a igualdade entre os gêneros [Teixeira , Moreira et al. 2016]. A Organização das Nações Unidas (ONU), por exemplo, estabeleceu dezessete Objetivos de Desenvolvimento Sustentável (ODS) e, dentre eles, encontra-se a igualdade de gênero. Entretanto, ao observar o cenário do mercado de trabalho, esse objetivo aparenta ser bem distante, uma vez que o homem ainda é considerado um padrão com o qual as mulheres devem ser comparadas e, em geral, ocupam cargos mais valorizados e recebem melhores salários [Mattos 2016].

No âmbito educacional e profissional é possível perceber um desequilíbrio na participação da mulher, sobretudo, nas áreas de ciências exatas e tecnológicas, caracterizada por uma tendência à existência de carreiras masculinas [Lima 2013, Borges et al. 2010]. No setor da Tecnologia da Informação (TI), a participação da mulher ainda está muito aquém do desejado. O estereótipo construído em torno dos estudantes, bem como os profissionais da área de tecnologia confirmam o cenário composto majoritariamente por homens [Lima 2014]. Entretanto, mesmo sendo minoria, muitas 
mulheres se destacaram na área [Schwartz et al. 2006] e ainda se destacam, como por exemplo, no que diz respeito às produções científicas mais significativas e de maior qualidade [Rosa and Quirino 2017].

Como forma de incentivar a diversidade de gênero dentro das organizações, muitas empresas de tecnologia investem em comunidades para o empoderamento de mulheres na área. As comunidades mostram-se boas iniciativas para promover trabalho, troca e produção de conhecimento [Moretti 2013]. Além disso, a comunicação desenvolvida nesse espaço permite a criação de um vínculo social entre os membros do grupo [Sartori and Roesler 2004].

Além das comunidades incentivadas por organizações, existem outras que partem de iniciativas próprias, sobretudo de mulheres. Em geral, essas comunidades surgem como um projeto para divulgar a área da tecnologia para outras meninas e mulheres [Moreira et al. 2016, Maciel et al. 2013] ou para manter relações entre mulheres que já são da área, como é o caso da comunidade apresentada neste estudo. Dessa forma, é objetivo do trabalho apresentar esse grupo, suas iniciativas e verificar se o fato da comunidade ser composta somente por mulheres faz com que as mesmas se sintam mais confortáveis, conforme apontam estudos recentes [Hirsch et al. 2017].

\section{A comunidade}

A comunidade "Minas da TI" foi criada no final do ano de 2015, após idealização das fundadoras, que são desenvolvedoras e, com frequência, sentiam sua capacidade questionada. Além disso, relatos de conhecidas, amigas e outras mulheres da área foram levados em conta para concluir a criação da comunidade voltada ao público de mulheres na área de tecnologia.

Diferentemente da maioria das comunidades já existentes voltadas a esse tema, essa optou por ser restrita à participação de mulheres. Isso porque observou-se que várias outras comunidades voltadas para o empoderamento feminino na região contavam com palestras ministradas, em sua maioria, por homens. E, além disso, nos encontros promovidos, a maioria dos participantes eram do sexo masculino. Dessa forma, o perfil atingido pela comunidade são jovens mulheres em sua maioria com idade entre 18 e 34 anos. Entretanto, na página da comunidade no Facebook, existe uma pequena parcela masculina, $24 \%$ do total de seguidores, que segue as publicações do grupo apesar dos eventos divulgados nessa página serem restritos ao público feminino.

Os encontros promovidos pelo grupo acontecem duas vezes por mês, contam com a presença de 20 a 25 mulheres e variam muito de formato. Em geral, ocorrem debates, palestras, dojos e workshops. Cada evento possui sua particularidade mas busca sempre levar o aprendizado de uma nova tecnologia. É muito importante que os encontros ocorram com certa periodicidade para que se crie uma rede de contatos e conexões mais fortes entre as participantes. Além disso, com o objetivo de divulgar e ganhar a adesão de mais mulheres, a comunidade incentiva as participantes veteranas a levarem outras mulheres para os encontros. Dessa forma, elas se sentem parte da comunidade e auxiliam no enriquecimento e crescimento da mesma.

Além do apoio recebido pelas próprias participantes dos eventos, o grupo conta com o apoio de várias empresas da região que contribuem cedendo espaços, patrocinando 
eventos ou até mesmo divulgando a comunidade. A comunidade também é reconhecida dentro das universidades, onde, frequentemente, as fundadoras palestram com o objetivo de incentivar as mulheres da área. Eventos assim aumentam a visibilidade da comunidade, assim como ocorreu quando o grupo foi divulgado em uma entrevista para um jornal local, o que fez com que o número de seguidores na página do Facebook dobrasse. Atualmente, a página no Facebook conta com 346 curtidas sendo que dessas, 273 são de mulheres e o grupo no Meetup possui 299 mulheres inscritas.

\section{Estudo Quantitativo}

Baseado no fato de que existem muitas comunidades mistas voltadas às mulheres na área de tecnologia, a principal questão que se deseja compreender é se o fato do grupo ser composto somente por mulheres faz com que, de fato, as membros se sintam mais confortáveis. Para isso, um questionário foi elaborado com duas perguntas principais, sendo elas: "Como você se sente estando em um grupo somente de mulheres?" e, caso a membro também participe de grupos mistos, "Como você se sente estando em um grupo misto?". Para ambas as perguntas, foi criada uma escala de 1 a 5, onde 1 representa desconfortável e 5 indica confortável. Além disso, para compor o perfil das mulheres que responderam ao questionário, foram feitas perguntas relacionadas à idade e escolaridade das mesmas.

O questionário foi enviado para o e-mail de todas as mulheres que fazem parte do grupo no Meetup com o objetivo de limitar o sexo das respondendes do questionário, ou seja, somente mulheres responderem o mesmo. O questionário ficou disponível por 5 dias e, ao todo, obtivemos 82 respostas. Com base na análise dessas respostas, foi possível confirmar o pefil das mulheres que compõem a comunidade no Facebook. As mulheres que responderam ao questionário são, em geral, jovens com idade entre 18 a 34 anos e com ensino superior em andamento ou concluído, assim como o perfil de mulheres que curtem a página da comunidade.

Os resultados para as duas perguntas principais mostram que a grande maioria, $72 \%$, se sente confortável em um nível máximo na escala em grupos formados somente por mulheres. Enquanto que dos $72 \%$ das mulheres que participam de grupos mistos, $45,8 \%$ se sentem confortáveis nesse mesmo nível. Além disso, a porcentagem restante para os níveis de conforto em grupos formados somente por mulheres se distribui pelos níveis 3 e 4 que somam 26,9\% e nível 2 com 1,2\%. Já para os níveis de conforto em grupos mistos, os níveis 1 e 2 recebem 1,7\% cada, e os níveis 3 e 4 somam 58,8\%. Conforme mostram, respectivamente, as Figuras 1(a) e 1(b).

Além disso, é possível perceber que o grau de conforto atribuído às comunidades mistas é, em geral, inferior ao atribuído às comunidades em que a participação é restrita às mulheres. Dessa forma, pode-se inferir que, as mulheres, de fato, percebem diferenças ao participar desses dois tipos de comunidade. Isso fica evidente ao avaliar as distribuições entre os níveis de conforto para as comunidades.

\section{Conclusão e Trabalhos Futuros}

Apesar de ambos os grupos, formados somente por mulheres e mistos, terem sido avaliados pela maioria das membros da comunidade como sendo confortáveis, através da análise dos resultados, fica claro que a porcentagem do nível máximo de conforto atribuído com o valor 5 é superior nas comunidades cujos participantes são somente do sexo feminino. 
Como você se sente estando em um grupo somente de mulheres? Bzresposta

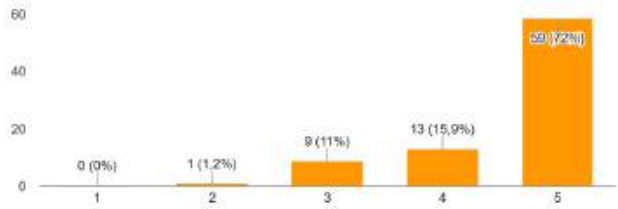

(a) Conforto das mulheres que participam de grupos formados somente por mulheres

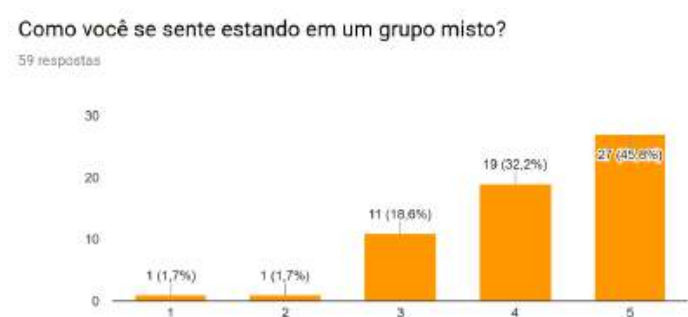

(b) Conforto das mulheres que participam de grupos mistos

Figura 1. Resultados quantitativos da pesquisa com as mulheres da comunidade. Na escala, 1 significa desconfortável e 5 significa confortável.

Sendo assim, acredita-se que a comunidade "Minas da TI" propicia um ambiente favorável para essas mulheres, uma vez que a maioria delas encontram-se também inseridas em grupos mistos. Dessa forma, a comunidade não pretende se abrir para a entrada de membros do sexo masculino.

Mesmo acreditando que diversidade de gênero é fundamental para se alcançar a igualdade de gênero, o grupo busca, em um primeiro momento, fortalecer a participação das mulheres no mercado de TI e amparar justamente o grupo que se sente mais confortável em participar de comunidades formadas somente por mulheres.

\section{Referências}

Borges, K. F. C., IDE, M. d. S., and Durães, S. J. A. (2010). Mulheres na educação superior no brasil: estudo de caso do curso de sistema de informação da universidade estadual de montes claros (2003/2008). In Congresso Ibero-Americano de ciência, tecnologia e gênero, volume 8.

de Freitas, L. B. and da Luz, N. S. Os estudos de gênero, ciência e tecnologia no brasil: Uma análise a partir de periódicos de gênero.

Hirsch, L. S., Berliner-Heyman, S., Cano, R., and Cusack, J. L. (2017). The effectiveness of single-gender engineering enrichment programs: A follow-up study.

Lima, F. A. d. (2014). Mulheres na tecnociência: depoimentos e vivências de mulheres nos cursos de computação da universidade tecnológica federal do paraná. Master's thesis, Universidade Tecnológica Federal do Paraná.

Lima, M. P. (2013). As mulheres na ciência da computação. Estudos Feministas, pages 793-816.

Maciel, C., Bim, S. A., and Boscarioli, C. (2013). Hci with chocolate: Introducing hci concepts to brazilian girls in elementary school. In CLIHC, pages 90-94. Springer.

Mattos, A. I. S. (2016). Desigualdades de gênero: Uma revisão narrativa. Saúde. com, 11(3).

Moreira, J., Mattos, G., Barreto, L., Cavaco, I., and Moreira, R. (2016). Atraindo meninas para a ciência da computação: Métodos e ferramentas. In Anais dos Workshops do Congresso Brasileiro de Informática na Educação, volume 5, page 1255. 
Moretti, G. (2013). Tecnologia e comunidades organizacionais: uma cultura digital? Comunicação Pública, 8(n13):99-122.

Rosa, M. A. G. and Quirino, R. G. (2017). Relações de gênero na ciência e tecnologia (c\&t): estudo de caso de um centro federal de educação tecnológica. Diversidade $e$ Educação, 4(8):42-55.

Sartori, A. S. and Roesler, J. (2004). Comunidades virtuais de aprendizagem: espaços de desenvolvimento de socialidades, comunicação e cultura. Acesso, 20:10-14.

Schwartz, J., Casagrande, L. S., Leszczynski, S. A. C., and Carvalho, M. G. d. (2006). Mulheres na informática: quais foram as pioneiras. cadernos pagu, 27(1):255-278.

Teixeira, D. V. Desigualdade de gênero: sobre garantias e responsabilidades sociais de homens e mulheres. Revista Direito GV, 6(1):253-274. 